\title{
Engineering in Steel Works and Collieries.
}

THE presidential address of Sir William Henry Ellis, delivered at the Institution of Civil Engineers on November 3, was devoted to a survey of the varied and difficult problems arising in steel works and collieries connected with the great development in mechanical engineering which has taken place during the last forty years. In the early part of this period, steel works engineering was in the hands of good practical men who could only with difficulty move with the times, owing to their lack of knowledge of the technical side of engineering. Low pressure steam was supplied to distant mill and machine shop engines with inevitable waste. Electricity probably did not exist in any of the large steel works. Highspeed tool steel was unknown, except Mushet steel, used more for its power of dealing with unexpectedly hard material than as high-speed steel is now used. There was, therefore, a great opportunity for young engineers who had received a combined technical and practical training to share in the work of introducing improved machinery. Economic production was not then so important, and there was comparatively little foreign competition.

The introduction of much higher steam pressures with water-tube boilers, and the advent of electricity, have been the two factors of the greatest help to steelworks engineers. To illustrate the advance-thirty years ago a large machine shop, with its inefficient driving and steam generation and distribution, was converting I.5 per cent. of the total energy of the coal into useful work. Now, by taking power from one of the latest and most efficient super power-stations in Great Britain, the shop can convert 17.38 per cent. of the thermal energy of the coal into useful work. This represents less than one-fifth of the energy available, and hence engineers cannot yet feel satisfied.

Developments in marine engineering caused the introduction of hollow rolling. Up to the time of the s.s. Lusitania turbine drums had been nearly all welded. Sir William was able to apply a process of punching and hollow rolling to the production of drums, in some cases more than thirty tons in weight. The process has revolutionised this important industry, and the results have been entirely satisfactory. What has always been wanted for this purpose has been a satisfactory ingot, cast hollow. At present Sir William and his colleagues are interested in experiments in this direction by means of centrifugal casting, this point being mentioned as an instance of the importance of the metallurgist and engineer co-operating in the closest possible way.

The physical properties of steel begin to change at temperatures at which steam is now used $-750^{\circ} \mathrm{F}$. and higher, and Sir William is carrying out a research on this point, with his metallurgical colleague Dr. W. H. Hatfield. The results of the series of tests being made will be useful to engineers who have to deal with the very high steam pressures employed. If still higher pressures with their corresponding temperatures are introduced, it may be necessary to use alloy steels, the physical properties of which are only affected at much higher temperatures.

No engineers are more definitely entrusted with the lives of their subordinates than mining engineers. Such engineers must possess an extremely varied knowledge, and it is very difficult for the mining engineer of a large colliery to be conversant with all the modern developments in mechanical engineering. Immense progress has been made in recent years in colliery engineering, but much remains to be done, and Sir William urges the desirability of the mining engineer having well-trained mechanical engineers on his staff. Such could render very great assistance to their chief.

Electricity has as yet been introduced into collieries only to a limited extent. No doubt electrical engineers may aid its use by further reducing the liability to sparking. Oil-immersed switches in closed boxes are a considerable safeguard, and the well-thought-out designs of main cables now in use appear to afford great security against risk of shortcircuiting in cases of falls of roof. Electric haulage in the workings has largely replaced the practice of surface engines with haulage ropes in boxes down the shafts. Electric winding has been introduced, and is making considerable progress.

Reference was also made to the work of the British Engineering Standards Association, which has now 475 committees and 2300 members. Engineers have shown great public spirit in giving time and attention to this great work-entirely on an honorary basis. Engineers and steel firms throughout Great Britain have generously supported the work by contributions to the funds, but this is a severe tax on industry in the present state of things, and it is earnestly hoped that some measure of Government help may be forthcoming.

\section{The Ignition of Gases.}

MANY of the difficulties connected with the ignition of gases are still unfathomed, although the subject has been investigated in one way or another from the time of Davy's well-known researches connected with safety in mines. Measurements of the rate of combustion were first attempted by Bunsen, but it was left to Berthelot, to Le Chatelier, and to Dixon to lay down the methods by which the propagation of combustion in gases could be satisfactorily studied. A further impetus to such investigations came with the development of the internal combustion engine. The recent work of Bone, which indicates that nitrogen plays a considerable part in the process of combustion, is particularly interesting and links the subject with the fixation of nitrogen. It was apt, therefore, that a discussion on the subject should have taken place at the meeting of the British Association at Southampton between the Chemistry and the Engineering Sections.
Prof. H. B. Dixon opened the discussion with a historical survey of the subject. He described Berthelot's discovery of the detonation wave and Le Chatelier's experiments on the same subject at the same date. Le Chatelier discovered three stages of combustion; the stage of uniform propagation, developing into a vibratory type of combustion which precedes the last stage, the initiation of the detonation wave. Prof. Dixon illustrated his remarks by some of his beautiful photographs of the propagation of explosions in mixtures of oxygen with cyanogen, acetylene, and other gases. The explosion wave travels with uniform velocity at the speed at which sound would travel in the gas, taking into account its high temperature and state of compression due to the combustion. Experiments on the measurement of ignition temperatures, which he has recently carried out by two different methods, were described. Tizard and Pye have shown that the delay which 
may occur before ignition when a combustible mixture is suddenly compressed adiabatically, depends on the temperature coefficient of the gaseous reaction. Ignition occurs when the heat evolved by the ignition of a gas just exceeds that lost to the surroundings. For the purpose of their experiments, Tizard and Pye used a variable compression machine with a piston which could be stopped by a toggle joint as soon as the gas had been compressed to the desired amount. Prof. Dixon described a similar arrangement by means of which the ignition point of electrolytic gas has been found to be continuously lowered as oxygen is added, in agreement with Le Chatelier's earlier experiments. With methane-air mixtures there is first a lowering, then a rise of the ignition point. It may be mentioned that Tizard and Pye, on the other hand, have found that for heptane-air mixtures the ignition temperature is only changed some $8^{\circ} \mathrm{C}$. when the heptane-to-air ratio is increased from I to ro. Prof. Dixon showed some interesting photographs of explosions occurring in gases compressed by his falling weight method; the combustion does not proceed from a point, but spreads out from an undefined region of luminosity.

The second method used by Dixon for the determination of ignition points depends on allowing a stream of inflammable gas to meet a stream of oxygen or air heated to the same temperature. This is effected by means of two concentric tubes surrounded by electric heating arrangements and so arranged that the gases can be introduced under high pressure or at reduced pressures. So long as the temperature is above a certain point, the gases on meeting ignite at a certain distance from the orifice of the tube. Increase of pressure as a rule decreases the temperature of ignition, but in the case of hydrogen, decrease of pressure also lowers the ignition temperature, even down to a pressure of one-tenth of an atmosphere.

Prof. David described his work on the effect of radiation on the rate of combustion of gas mixtures in a closed vessel. He finds the radiation which is effective is that which is absorbed by the combustible gas, but that no speeding up occurs if there is no nitrogen present. The radiation $4.4 \mu$ is absorbed by carbon monoxide and speeds up the combustion of carbon monoxide, oxygen, and nitrogen; while $3 \cdot 2 \mu$ radiation is absorbed by methane and speeds up the combustion of methane, nitrogen, and oxygen mixtures. If the nitrogen is replaced by argon, oxygen, or carbon dioxide, no speeding up occurs. The rate of rise of pressure measured by means of an optical indicator determines the amount of the speeding up. The effect of radiation is shown not to be due to the inhibition of formation of oxides of nitrogen. Prof. David suggests that the radiation tends to inhibit the temporary association between the nitrogen and the combustible gas, which normally occurs according to his view. Bone has found that nitrogen plays a considerable part in combustions at high pressures, the rate of combustion being much slower when nitrogen is present, the effect being attributed to "activation" of the nitrogen. There result considerably greater amounts of oxides of nitrogen than otherwise would be expected.

When ignition of a combustible mixture occurs in a closed vessel, the rate at which the flame spreads depends on the rate of communication of ignition from layer to layer of the gas and the rate at which the mixture moves under the expansive force of the burning gas. Dr. O. C. Ellis described the method by which he has studied this phase of the subject; work which has been undertaken for the Safety in Mines Research Board. A mechanically controlled camera is arranged to take a series of photographs of the advancing flame; the final photograph has the appearance of being divided into alternate dark and light zones, the exposures being intermittent. For weak mixtures - mixtures near the limit of ignitibility-the lightness of the burning portion compared with the surrounding unburnt gas together with the convection currents which outrun the flame and return upon it, determine the propagation and spread of the flame. For stronger mixtures, burning first occurs at nearly constant pressure; in this case the effect of the enclosure makes itself manifest and the flame moves to the more open space. If there is an opening the flame will move towards it. In a spherical vessel with central ignition, the flame would spread as if to reach all parts of the wall at the same time, but if convection currents have time to influence the combustion, the spread will be quicker in the upward than in the downward direction.

A glow has been found to occur in the flame products and lasts longer than the time taken for the primary flame to spread throughout the vessel. The duration of the afterglow appears to vary with the amount of water present; the glow is greater when argon is used as a diluent rather than when excess of carbon monoxide or nitrogen is present. The glow appears to be due to burning of combustible gas which has escaped the passage of the flame. It is not mainly due to oxidation of carbon monoxide, because in mixtures of oxygen and excess of cyanogen, brilliant periods of residual burning are found.

The incompleteness of combustion and the continuance of processes of combustion after passage of the flame was one of the points brought out by this discussion. Another point, which will no doubt repay further investigation, was the very considerable part played by nitrogen in processes of combustion.

\section{Ornithologists at Berlin.}

THE seventy-fifth anniversary of the German Ornithological Society was celebrated in Berlin on October 3-7. The meeting was more like a congress, nearly two hundred members attending, including representatives of eight different countries, in addition to those from all parts of Germany. The programme was full and varied.

On the first evening of the celebrations, an opening address was given by the president, Dr. von Lucanus, and the addresses and congratulations from the ornithological societies of other countries were read and presented. Dr. Ernst Hartert and Mr. Gregory, M. Mathews represented the British Ornithologists' Union. Dr. Stresemann compared the status of ornithology in $185^{\circ}$ and 1925 . The lectures referred chiefly to Mediterranean and African ornithology: Lönnberg (Stockholm), on the influence of periods of climate on the African ornis; Spatz (Berlin), on Crete; Hartert (Tring), on Atlas and Sahara; Reiser (Vienna), on the present knowledge of the ornis of the Balkans; Koenig (Bonn), on the White Nile; Heck and Neumann (Berlin), on Abyssinia, and so on. Other lectures were concerned with bird-migration: Geyr von Schweppenburg (Münden), Drost (Heligoland), Drescher (Ellguth), especially the results of ringing; with systematic studies and distribution: Kleinschmidt, Freiherr von Berlepsch and others; and ecology: Heyder (Oederan). Most interesting

NO. 2925 , VOL. I I 6 ] 